\title{
Failure modes and mechanisms for flood defence structures
}

M.W. Morris, W. Allsop, F.A. Buijs, A. Kortenhaus, N. Doorn \& D. Lesniewska

Reproduced from:

Flood Risk Management - Research and Practice Proceedings of FLOODrisk 2008

Keble College, 0xford, UK

30 September to 2 October 2008 


\title{
Failure modes and mechanisms for flood defence structures
}

\author{
M.W. Morris, W. Allsop \& F.A. Buijs \\ HR Wallingford, Wallingford, UK
}

\author{
A. Kortenhaus \\ N. Doorn \\ Previously of WL/Delft Hydraulics, Delft, the Netherlands \\ D. Lesniewska \\ Institute of Hydroengineering, Polish Academy of Science, Gdansk, Poland
}

Technische Universität Braunschweig, Leichtweiß-Institut für Wasserbau, Braunschweig, Germany

\begin{abstract}
In order to undertake a flood risk analysis, the performance of different flood defence structures under varying load conditions needs to be represented. This paper reports on work undertaken through the FLOODsite Project (Task 4) in bringing together available information on failure modes for a number of representative flood defence structure types, to support the development and implementation of system wide models for flood risk assessment. The work comprised a review of structures and failure modes which have occurred in the past, and an investigation of limit state equations and associated uncertainties for both the models and the input parameters. Summaries of all failure modes were combined to create a single reference document; it is hoped that this will be maintained and updated into the future as knowledge on different failure mechanisms evolves. Additional research into selected failure modes and embankment processes was also undertaken and is summarised in this paper, including recommendations as to areas where future research should be focussed.
\end{abstract}

\section{INTRODUCTION}

The European Integrated Project FLOODsite (www. FLOODsite.net) aims to provide better understanding and improved methodologies for flood risk analysis and flood risk management. This includes consideration of flood risk from river-basins, estuaries and coasts, from a range of perspectives and users. FLOODsite is subdivided into different Themes, one of which (Theme 1) deals with improved understanding of the underlying physics needed to perform a flood risk analysis. Within Theme 1, Task 4 addresses flood defence failure mechanisms and the development of a definitive document detailing different failure modes for a wide range of defence types and loading. The understanding and analysis of flood defence failure mechanisms was identified as a critical area of research where improved knowledge on processes and their representation through limit state equations was urgently needed. In order to undertake a flood risk analysis, the performance of different flood defence structures under varying load conditions needs to be represented. The work in Task 4 addressed the review, collation and refinement of failure mode information, as well as research into some specific defence failure processes. The objective was to bring together all available information on failure modes, for a wide range of flood defence structures, to support the development and implementation of system wide models for flood risk assessment. This paper describes the key elements of research dealing with failure modes for flood defence structures, leading to the production of the FLOODsite report T04-06-01 (FLOODsite, 2007a), Failure Mechanisms for Flood Defence Assets (available online from www.FLOODsite.net). The work comprised a review of structures and failure modes which have occurred in the past, investigation of limit state equations and associated uncertainties for both the models and the input parameters, and some additional defence specific investigations to improve knowledge of failure processes (including embankment and shingle beach failure processes). It is envisaged that this report will be maintained and updated in the future.

This paper provides an introduction to flood risk assessment in Section 2, including an overview matrix of failure mechanisms for the main flood defence structure types and hydraulic load conditions 
(FLOODsite, 2007a). Section 3 provides some examples of failure mechanisms of the main flood defence structure types, whilst Section 4 contains a brief summary of additional research actions into specific failure mechanisms and processes leading to a summary (Section 5) of gaps in knowledge and recommended future research direction. Overall observations and conclusions are presented in Section 6.

\section{FAILURE MECHANISMS IN FLOOD RISK ASSESSMENT}

\subsection{Flood risk assessment}

A flood risk assessment requires consideration of the likelihood of flood defence failure under different hydraulic loading conditions, and estimation of the (economic) damages associated with different inundation scenarios. A flood defence system protecting a floodplain usually consists of a number of different types of flood defence structure. The failure mechanisms of each of the structure types are analysed. The failure mechanisms may be organised in a fault tree, which represents the different chains of events leading to an overall failure of the flood defence structure (top event). In a quantitative flood risk assessment, reliability theory is applied to calculate a probability of failure. Reliability theory describes the strength $R$ and loading $S$ of a failure mode by means of process models in a limit state equation,

$$
Z=R-S
$$

whereby the structure fails when the loading exceeds the strength, i.e. for $Z \leq 0$. Often process models of varying detail exist for different failure mechanisms.

Though the design and asset management of flood defences requires detailed understanding of failure mechanisms, flood risk assessments currently rely mainly on approximate descriptors of the strength and loading of the flood defence. In a flood risk assessment context it is not always feasible to apply a detailed process model, for example application of finite element modelling techniques. Equally, for some failure mechanisms only superficial process models exist.

A risk assessment should incorporate as detailed description of the failure mechanism as possible, whilst adopting a level of detail which is appropriate for the particular application and use of the analysis results. The FLOODsite failure mechanisms report (FLOODsite, 2007a), supplies over 80 descriptors of different failure modes and defence structures in the form of limit state equations. These limit state equations are subsequently embedded within a tool to calculate the reliability of a flood defence structure (developed in Task 7 of FLOODsite (FLOODsite, 2008)). For the detailed design and asset management of flood defence structures the reliability analysis can be complemented with a more comprehensive qualitative or quantitative failure mechanism analysis. The emphasis of this paper is to provide an introduction and example of how the failure mechanisms have been implemented in the report, and to highlight areas where further research is needed to understand recognised failure mechanisms. The identification of gaps in our knowledge is a logical outcome of the systematic collation and review of existing failure mode knowledge.

\subsection{Failure mechanism matrix}

Figure 1 displays a matrix of different structure types against different types of hydraulic loading. The codes shown within boxes in the matrix refer to failure mechanisms detailed within the failure modes report (FLOODsite, 2007a) and hence in the subsequent reliability tool. The boxes shaded green represent structure-load combinations where a failure mode has been defined. A grey box with no reference reflects a load-structure combination that does not, or is unlikely to exist. A white box with reference reflects a failure mode for that load-structure combination which has already been defined elsewhere in the matrix. A red box indicates a load-structure combination for which a failure mode model was not found.

The matrix (Figure 1) contains a selection of the main flood defence asset types. Failure mechanisms are classified by generic flood defence type and loading categories. However, in practice many variations of flood defence type exist, and are either completely different from those listed in Figure 1 or a combination of those asset types. Each unique flood defence structure can fail according to generically applicable failure mechanisms as well as specific failure mechanisms. Examples can include the presence of foreign objects or tension cracks and transition structures within generic structure types. In the 'foreshore, dunes and banks' category, a distinction is made between fine granular material, e.g. beaches or dunes, and coarse granular material, such as shingle, gravel or rock beaches. The flood defence category 'embankments and revetments' classifies homogeneous, composite embankments and revetment structures. The 'vertical wall structures' category is divided firstly into gravity based structures, such as mass concrete, vertical or battered walls, secondly sheet pile structures, i.e. cantilever or tied back, and finally crown or parapet walls on structures. In the 'point structures category' barriers or sluices and gates are distinguished.

As with the classification into flood defence asset types, the matrix (Figure 1) also distinguishes generic 


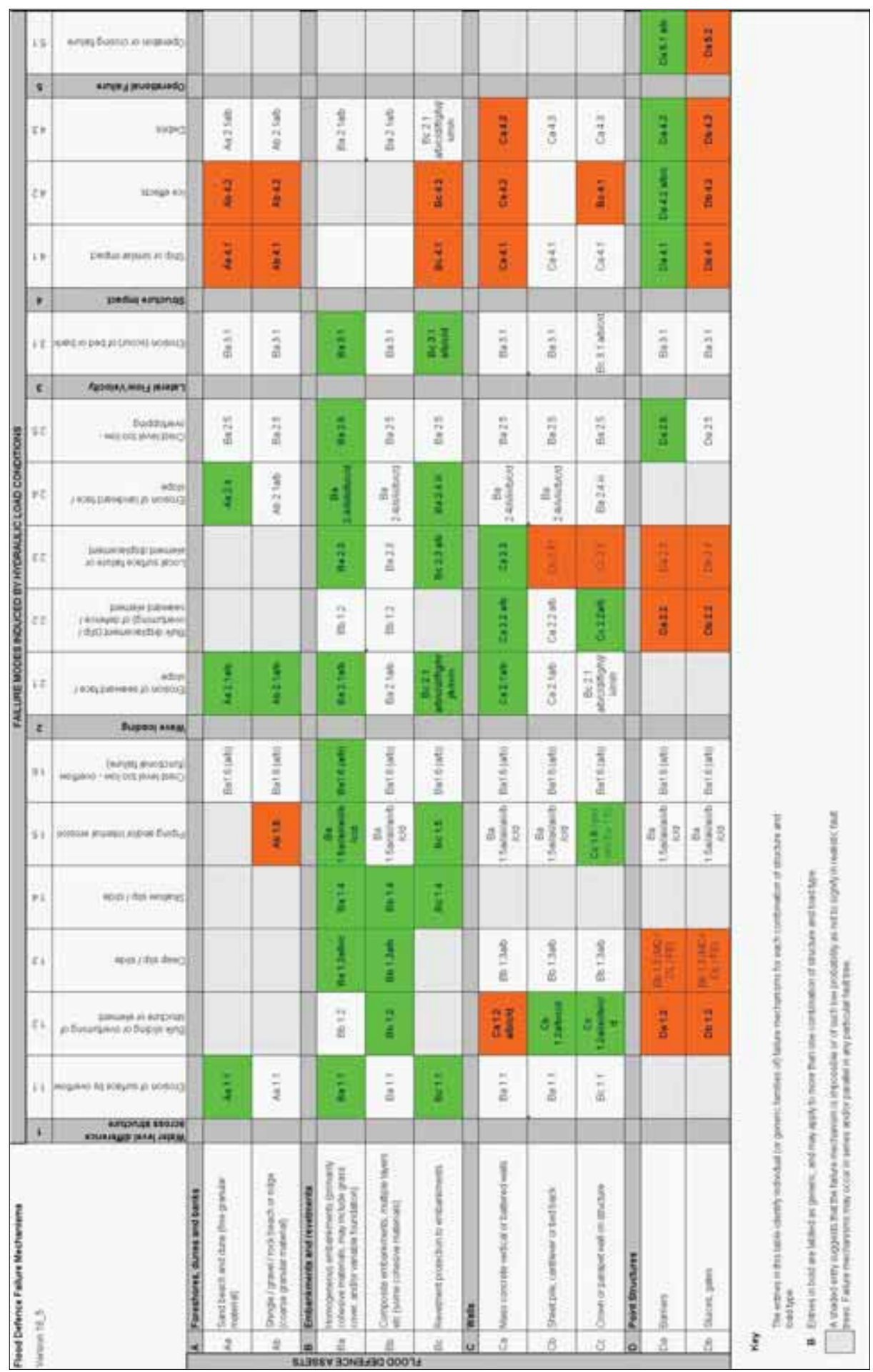

Figure 1. Failure mechanism matrix for different flood defence structure types and hydraulic loading conditions. 
categories of hydraulic loading conditions: water level difference across the structure, wave loading, lateral flow velocity, structure impact and operational failure. Again, in practice, many different kinds of hydraulic loading conditions occur possibly initiating, depending on the structure type, site specific failure mechanisms in addition to the generic failure mechanisms. Examples include differential loading in case of rapidly varying water levels, the impact of channel bends, vortex shedding in the case of sharp corners in the flood defence alignment or ship-induced currents and waves.

Deterioration or time-dependent processes are not included in the failure mechanism matrix. Failure processes consist of i) failure modes, i.e. a chain of events leading to failure during an event; ii) long term time-dependent processes affecting the flood defence performance either negatively (deterioration) or positively (e.g. beach morphology). The scope of this work within FLOODsite was limited to failure modes. Deterioration or time-dependent processes influence one or more flood defence characteristics in the process models of a failure mechanism. The change in the failure mechanism induced by the timedependency introduces time-dependency in the probability of flood defence failure. The influence of such time-dependency is not considered in more detail here, but studies are now beginning under for example HR Wallingford (2004) or Buijs (2008).

\section{FAILURE MECHANISMS OF STRUCTURE TYPES}

FLOODsite (2007a) contains over 80 limit state equations, which cannot be presented in detail within this paper. Instead, the emphasis here is on providing an impression of how the failure mechanisms have been implemented within the report and subsequently programmed into a reliability tool (FLOODsite, 2008). Some examples of failure mechanisms for the flood defence structure types in Figure 1 are presented in the following sections. FLOODsite (2007a) is set up in the form of templates containing a graphic representation of the failure mechanism, the equation, or equations, for the process model and references.

\subsection{Foreshore, dunes and banks}

The main failure mechanism which is considered for dunes performance is erosion of the seaward face by waves (Vellinga, 1986, or CIRIA, 1996), corresponding with matrix template reference Aa2.1a. The process model predicts the shape of the dune front slope under wave attack and evaluates whether the dune volume is sufficient to withstand the storm wave conditions. FLOODsite (2007a) presents the equation according to Vellinga (1986) and applies a simplified integration of the dune profile. The supletion of dunes tends to be directed at limiting the probability of failure due to wave overtopping or overflow as lower than failure due to erosion by wave attack. Predictive process models for wave overtopping discharges capturing the dynamic behaviour of dunes are not available.

The main failure mechanism which is applied to the performance of shingle beaches is Powell (1991), see also CIRIA (1996). The shingle process model predicts the shingle profile during storm conditions and evaluates whether the shingle volume is sufficient to withstand the storm wave conditions. FLOODsite (2007a) presents a simplified equation that evaluates the crest retreat during storm wave conditions (template Ab2.1a). The approach is meant to support situations where limited information on the shingle volume in the profile is available. Similar to dunes, there is no process model to predict wave overtopping or flow discharges over or through the shingle beach.

It is possible to define site specific $2 \mathrm{D}$ process models, physical models or forecasting based on historical time series of dune or beach profiles. Such methods have not yet been implemented in a quantitative flood risk assessment.

\subsection{Embankments and revetments}

Embankments have been studied extensively. Process models of various qualities are available for different components of an embankment: inside slope, outside slope, embankment core and foundation. Many of these limit state equations have been applied in a probabilistic context. Some of the failure mechanisms in FLOODsite (2007a) do not lead to full structural failure alone. An example is given in Figure 2 for grass erosion due to wave overtopping in combination with a breach formation model.

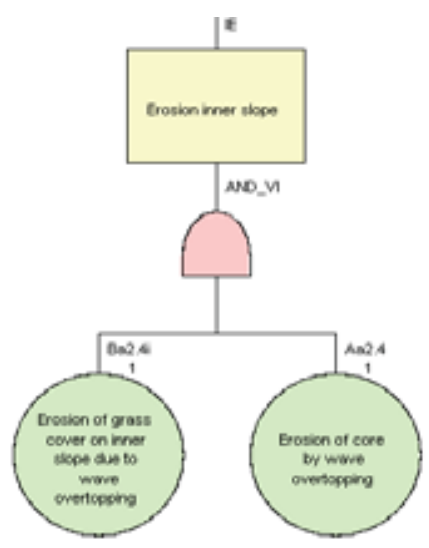

Figure 2. Example of fault tree whereby wave overtopping is combined with a breach formation model. 


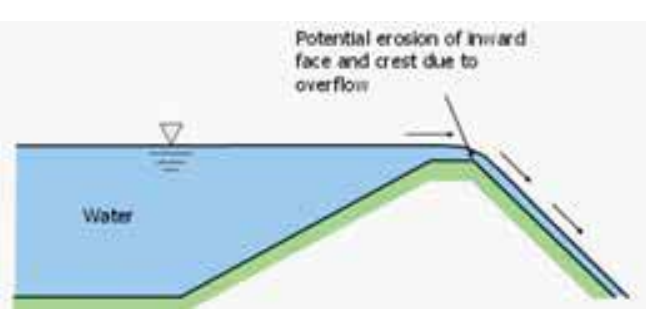

Figure 2 Overtopping and erosion of the grass cover on the inside slope.

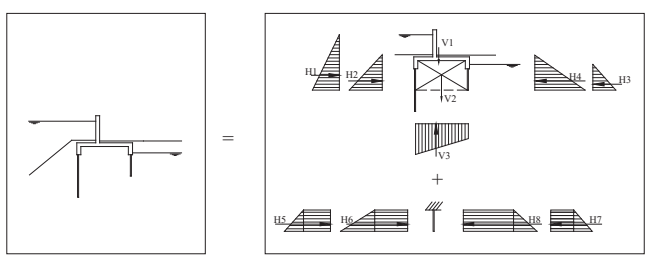

Figure 3 Example of an anchored sheet pile wall and its loading.

The limit state equation for overtopping and grass erosion (template $\mathrm{Ba} 1.1$ ) is given below. The failure mechanism describes the situation where the grass cover on the inside slope fails due to loading by (wave) overtopping discharges, Young (2005) (Figure 2):

$\mathrm{z}=\mathrm{m}_{\mathrm{qc}} \cdot \mathrm{q}_{\mathrm{c}}-\mathrm{m}_{\mathrm{q} 0} \cdot \mathrm{q}_{0}$

in which $\mathrm{q}_{\mathrm{c}}$ is the critical overtopping discharge for which the grass cover fails, $m_{\mathrm{qc}}$ represents the model uncertainty in the critical discharge, $\mathrm{q}_{0}$ is the overtopping discharge which is calculated by the weir equation for overflow, or with an appropriate (wave) overtopping process model. The critical discharge is derived as follows:

$$
\mathrm{q}_{\mathrm{c}}=\mathrm{v}_{\mathrm{c}}^{3} /\left(\tan \alpha_{\mathrm{i}} \cdot \mathrm{C}^{2}\right)
$$

in which $\mathrm{v}_{\mathrm{c}}$ is the critical velocity of the flow on the grass cover $(\mathrm{m} / \mathrm{s}), \alpha_{i}$ is the angle of the inside slope $\left({ }^{\circ}\right), \mathrm{C}$ is the roughness on the inside slope according to Chézy $\left(\mathrm{m}^{0.5} / \mathrm{s}\right)$, which is estimated by:

$$
\mathrm{C}=25 \cdot\left(\mathrm{q}_{\mathrm{c}} / \mathrm{k} \cdot \mathrm{v}_{\mathrm{c}}\right)^{1 / 6}
$$

whereby $\mathrm{k}$ is the roughness length $(\mathrm{m})$ and the critical velocity $\mathrm{v}_{\mathrm{c}}$ is given by:

$$
\mathrm{v}_{\mathrm{c}}=\frac{3.8 \cdot \mathrm{f}_{\mathrm{g}}}{\left(1+0.8^{10} \cdot \log \mathrm{t}_{\mathrm{e}}\right)}
$$

in which $f_{g}$ is the erosion strength of grass $(-)$ and $t_{e}$ is the (wave) overtopping duration (h).

\subsection{Vertical wall structures}

FLOODsite (2007a) contains failure mechanisms for gravity based structures as well as sheet pile wall structures. Failure mechanisms for gravity based wall structures represent instability, such as sliding, as well as surface failure of, for example, reinforced concrete. Gravity based walls can consist of a number of different materials types such as masonry or concrete. In FLOODsite (2007a) only failure of reinforced concrete under hydraulic loading is covered.

Figure 4 shows an example of a limit state condition for the sliding failure of a reinforced concrete wall. The concrete wall is loaded by the water level in the form of horizontal and hydraulic uplift forces. This loading is balanced by the weight of the concrete wall, the soil mobilised between the sheet pile cut-offs and the horizontal ground pressures. Consequently:

$$
\mathrm{z}=\mathrm{m}_{\mathrm{c}, \mathrm{s}, \mathrm{R}} \cdot \tan \delta \cdot \sum \mathrm{V}-\mathrm{m}_{\mathrm{c}, \mathrm{s}, \mathrm{S}} \cdot \sum \mathrm{H}
$$

in which $\delta$ represents the friction between the foundation of the concrete wall and the soil, $\Sigma \mathrm{V}$ is the resulting vertical force, $\Sigma \mathrm{H}$ is the resulting horizontal force, $\mathrm{m}_{\mathrm{c}, \mathrm{s}, \mathrm{R}}$ is the model uncertainty for the strength of the concrete wall and $m_{c, s, S}$ is the model uncertainty for the loading of the concrete wall.

$\mathrm{H}_{\text {total }}=\left(\mathrm{H}_{1}+\mathrm{H}_{2}+\mathrm{H}_{5}+\mathrm{H}_{6}\right)-\left(\mathrm{H}_{3}+\mathrm{H}_{4}+\mathrm{H}_{7}+\mathrm{H}_{8}\right)$

$\mathrm{H}_{\text {total }}$ is the resulting horizontal force $\Sigma \mathrm{H}$ in equation (6). $H_{1}$ is the hydraulic loading on the reinforced concrete wall, which can be complemented with a horizontal wave impact model. $\mathrm{H}_{2}$ is the horizontal grain force exerted by the soil on the riverside, $\mathrm{H}_{5}$ is the hydraulic force on the sheet pile cut-off on the riverside, $\mathrm{H}_{6}$ is the horizontal grain force on the sheet pile cut-off on the riverside. $\mathrm{H}_{3}$ is the hydraulic force of the ground water level on the landside,

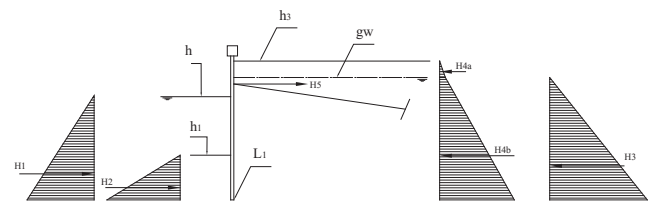

Figure 4. Example of an anchored sheet pile wall and its loading. 
$\mathrm{H}_{4}$ is the horizontal grain force on the concrete wall on the landside, $\mathrm{H}_{7}$ is the groundwater force on the sheet pile cut-off on the landside, $\mathrm{H}_{8}$ is the grain force on the sheet pile cut-off on the landside. One of the failure mechanisms for anchored sheet pile walls is breaking of the tie rod (Figure 5). The horizontal ground pressures on the steel sheet pile wall are balanced by the tie rod. The tie rod breaks if the yield stress is exceeded by the loading pressures, hence:

$\mathrm{z}=\mathrm{m}_{1} \mathrm{~F}_{\mathrm{u}}-\mathrm{m}_{2} \cdot \mathrm{F}_{\text {tot }}$

in which $F_{u}$ is the ultimate force in the steel sheet pile tie rod, $m_{1}$ is the model uncertainty related to the strength of the tie rod, $\mathrm{F}_{\text {tot }}$ is the total loading force in the tie rod, $m_{2}$ is the model uncertainty in the total loading force in the tie rod. $\mathrm{F}_{\mathrm{u}}$ is given by:

$\mathrm{F}_{\mathrm{u}}=\mathrm{A}_{\mathrm{s}} \cdot \mathrm{f}_{s}$

whereby $A_{s}$ is the area of the tie rod and $f_{s}$ is the yield stress of the tie rod steel. $F_{\text {tot }}$ is the total loading force in the anchor:

$\mathrm{F}_{\text {tot }}=\mathrm{H}_{5} \cdot \frac{\mathrm{w}_{\mathrm{a}}}{\cos \alpha}$

$\mathrm{H}_{5}$ is the horizontal force in the tie rod, $\mathrm{w}_{\mathrm{a}}$ is the number of anchors per stretching meter pile, $\alpha$ is the angle of inclination of the anchor.

$\mathrm{H}_{5}=\left(\mathrm{H}_{4}+\mathrm{H}_{3}-\left(\mathrm{H}_{1}+\mathrm{H}_{2}\right)\right)$

$\mathrm{H}_{4}$ is the ground force on the landside, $\mathrm{H}_{3}$ is the force exerted by the ground water, $\mathrm{H}_{1}$ is the force of the river water level and $\mathrm{H}_{2}$ is the ground force on the riverside.

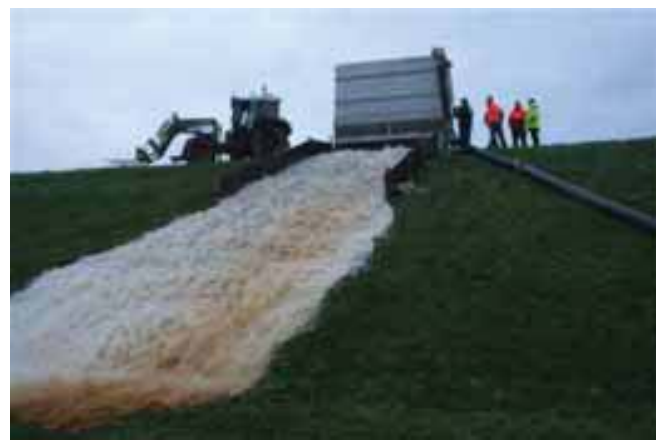

Figure 5. Wave overtopping simulator.

\subsection{Point structures}

Barriers, sluices or gates are all systems of components which need a specific failure analysis. In addition, there can be failure due to piping underneath the hydraulic structure or operational failure mechanisms possibly in combination with the exceedance of the storage area behind the structure. Eight failure mode templates are provided in FLOODsite (2007a) but solutions for a larger number of structure load combinations were not available. Point structures form one of the areas where additional research is required to improve knowledge of failure modes details.

\section{SUPPORTING RESEARCH ON FAILURE MECHANISMS}

In addition to compiling current knowledge on failure modes, a range of additional research was also undertaken under Task 4 of the FLOODsite project to improve our understanding of specific defence structure failure modes and embankment condition. This research is briefly summarised below.

\subsection{Performance of grass cover}

UNESCO IHE Institute for Water Education undertook a review of the performance of grass on the inner slopes of flood embankments under wave overtopping (Young, 2005). Current design practice typically uses average overtopping discharge as a performance condition, yet recent research shows that overtopping flow velocities from individual waves may exceed $4 \mathrm{~m} / \mathrm{s}$ creating shear stresses on the grass of up to $0.4 \mathrm{kPa}$.

Source data for the CIRIA Report 116 steady flow erosion model was considered. The research illustrates that this model is not valid for use with short duration, very high velocity flow on steep slopes, such as the conditions that can occur during overtopping.

Analysis of potential failure mechanisms resulting in turf set-off was undertaken. A reliability function for turf stability, which models composite action from root cohesion, based on a surface sliding mechanism, was developed and is included within the failure modes report (FLOODsite, 2007a).

\subsection{Wave overtopping simulator and large scale flume tests}

Two additional research actions have assisted in improving our knowledge of grass performance under wave action. A wave overtopping simulator was developed and tested by INFRAM, as part of both the FLOODsite and ComCoast projects (Figure X, FLOODsite 2007b). The simulator allows 
direct testing of embankment grass cover performance under controlled flow conditions. Water is released from the simulator in pulses to simulate conditions that would occur during wave overtopping. The simulator provides a means for directly comparing overtopping and equivalent overflowing conditions, and hence the validity of existing design assumptions for overtopping protection performance.

In parallel, the Technische Universität Braunschweig have undertaken a series of laboratory tests culminating in large scale wave tests on sections of real coastal embankment extracted from embankments in Denmark. These tests focus upon grass performance under wave impact, as well as overall breach initiation and growth. Details of this work are reported in another paper at FLOODrisk2008 (Morris et al, 2008). These tests have shown that for the conditions tested, grass has proven to be much more resistant than initially assumed. Whilst the overtopping simulator has generated overtopping events up to as much as $50 \mathrm{l} / \mathrm{s} / \mathrm{m}$ with almost no damage to the grass observed, tests with significant wave overtopping in the large wave flume of Hannover were not able to erode the grass and the underlying clay cover.

\subsection{Air trapping and cracking in embankments}

Research into internal cracking of embankments was undertaken to understand more about how earth embankments can deteriorate through the development of internal cracks and slip planes as a result of intensive short term infiltration that might arise, for example, from wave overtopping or heavy rainfall.

A series of laboratory tests were undertaken showing how rapid inundation of a previously dry embankment can lead to partially saturated soils, with areas where air becomes trapped. By using a clear sided flume with an array of pressure sensors and high density digital cameras, the fluctuations in air pressure within the soil and subsequent growth of cracks leading to slip surfaces was observed (Figure 6).

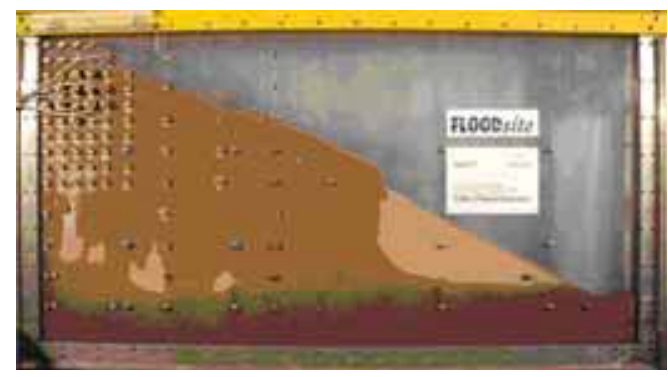

Figure 6. Infiltration into a test embankment showing saturated zones and trapped pockets of air.
More information on this research into fundamental processes can be found in FLOODsite, 2007c.

\subsection{Performance of shingle beaches}

Shingle beaches perform an important flood defence role and hence their performance under varying load conditions needs to be understood to determine flood risk. A series of physical model tests were undertaken at HR Wallingford to investigate shingle beach performance under varying wave load, geometry and sediment conditions. Analysis of the resulting data allowed the refinement of existing relationships for the failure of shingle beaches. Details of the physical model testing and analysis can be found in FLOODsite, 2007d. Details of this failure mode analysis were also included within the failure modes report (FLOODsite, 2007a).

\subsection{Embankment integrity assessment- use of geophysics}

With different embankment failure modes arising as a function of material type and state, discontinuities and boundaries there remains a strong need for a simple, fast and cost effective way of establishing the state of long lengths of flood embankment. Current approaches typically jump between the two extremes of visual inspection or intrusive site investigation. Visual inspection cannot provide detailed information on the conditions inside an embankment, whilst intrusive site investigations are not cost effective for long lengths of embankment.

Research into the use of multi-frequency dipole electromagnetic profiling provided a methodology for embankment assessment within the European IMPACT Project (IMPACT, 2005). This initial work was tested and validated during the FLOODsite project. By using multiple frequencies, the resistivity of soils at different depths throughout the embankment can be measured simultaneously. By considering changes in resistivity by location and test conditions (i.e. wet, dry etc) high risk zones may be identified. These typically correspond to areas showing significant changes in resistivity, reflecting boundaries between material types, construction works or seepage routes. The equipment can be carried, and data recorded in conjunction with a GPS system (Figure 7). Analysis of the data typically requires expert knowledge in order to interpret how resistivity trends may reflect embankment conditions.

Through the later Gemstone project, a working system, including GIS database for storing and mapping results, has been developed and is currently being applied in a number of river catchments within the Czech Republic. Details of this work can be found within another FLOODrisk2008 paper (Boukalová \& Beneš, 2008). 


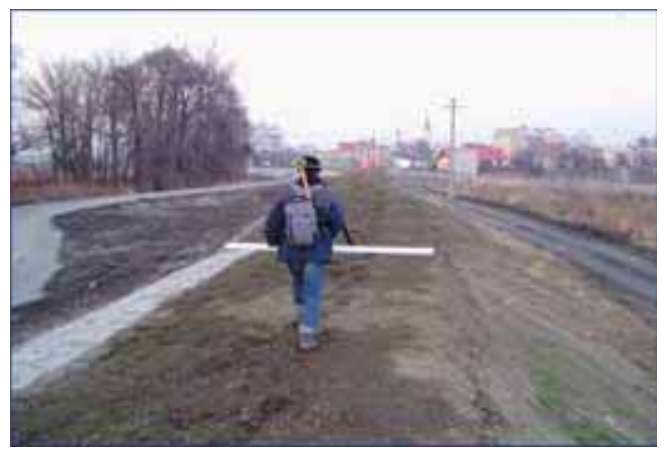

Figure 7. Survey of embankment by electromagnetic profiling.

\section{GAPS IN KNOWLEDGE AND FUTURE DIRECTION}

The review and collation of failure mode information in to templates within the failure modes report has provided a central reference of material that is freely available (www.floodsite.net) and which can be used to support system wide models for flood risk assessment. The process of collation and editing this document, along with implementation of the various specific research actions, has also highlighted areas where little or no information exists and hence where future research efforts might be directed.

Four areas identified directly from the failure modes report are:

1. Structure-load combinations shaded red in the failure modes matrix. These represent combinations for which solutions were not found or immediately available. A total of 28 boxes are shaded red, of which 21 represent unique structure-load combinations for which we require failure mode information. The remaining 7 potentially duplicate existing failure mode solutions. This compares against a total of 96 boxes with solutions, where 36 are unique and 60 are duplicates. In general there is a tendency for the missing failure mode information to relate to the failure of walls and point structures for all load types, and for all structure types under impact and operational failure conditions.

2. Transitions between structures - the hurricane damage in New Orleans in 2005 highlighted the significant weaknesses that exist in flood defence systems at transitions between structures. The combination of poor design and/or construction detail can result in a focus of hydraulic loading at a weak point in the system.

3. Time dependent processes - present capabilities for system modelling do not allow for time varying processes. For example, how asset condition may deteriorate during continued hydraulic loading or over longer periods of time (i.e. intra storm loading; longer term deterioration). Examples of deterioration include joint deterioration in block or brickwork or fissure/crack development in embankments

4. Point structures - come in many varying designs and sizes and invariably entail transitions between asset types. Point structures can contain a large number of ways in which the flood defence system may be compromised. Detailed performance information for point structures appeared limited and difficult to collate.

Three additional areas requiring further research and identified as part of the FLOODsite reliability analysis work are:

5. Failure modes for real, composite structureswhilst failure mode analysis starts with solutions for simple, generic structures, the reality is that many flood defence structures are variations from the generic and may comprise a combination of different structures. Expanding the database of failure mode templates for an increasing range of structure designs will help reduce uncertainty within the flood risk analyses.

6. Three dimensional effects - failure mode analysis considers structures in two dimensions however three dimensional effects such as flow around structures, defences or within the river plan form can focus loading at a point in the defences leading to failure.

7. Interaction between failure modes - existing failure mode analysis considers individual failure modes, or perhaps through a fault tree a conditional series of failure modes. In reality, the failure process can transition or oscillate between a number of failure processes which by themselves might not have resulted in failure, but in combination can lead to failure.

The specific research activities on aspects of embankment performance also highlighted several areas where further research is needed:

8. Wave overtopping design guidance-with development of the wave overtopping simulator, research can now be undertaken to establish how reliable simplifying assumptions, such as acceptable (steady) overflow rates representing overtopping is in relation to the design performance of grass or other vegetation cover.

9. Vegetation performance - reviews of both design guidance and vegetation performance in relation to breach initiation have identified that whilst initial research was undertaken in the 
1980s (CIRIA, 1987) there has been little further work to validate and extend this guidance in the following two decades. Current research findings are starting to question the applicability of these design curves to various load conditions.

10. Internal erosion and seepage-whilst models exist to predict how flow through a pipe or hole in an embankment might progress through to failure, models are poor or non existent for predicting the initial stages of seepage path development and the time of development through to a stage where seepage is observable.

\section{CONCLUSIONS}

The FLOODsite project has provided the basis for a significant step forward in understanding and formalising failure modes for flood defence structures. Through collaboration across Europe, the failure modes report (FLOODsite, 2007a) now provides a definitive collection of failure mode descriptions for different flood defence structures and loading conditions which may be used to support system wide flood risk modelling. It is hoped that this report provides the first edition of a living document that can be extended and updated as new knowledge emerges for different failure modes, structure types and load conditions.

In addition to the failure modes report, a considerable range of research activities focussing upon different aspects of flood embankment performance have been undertaken. Details of this research are only briefly mentioned in this paper and the reader is encouraged to follow the references provided for a more thorough understanding of the work undertaken. These various actions have advanced understanding of embankment performance and supported the development of new failure mode templates within the failure modes report. Additionally, the research has helped provide a focus for the priorities of future research in this area.

All FLOODsite technical reports referenced in this paper are, or will be available through the project website at www.floodsite.net

\section{ACKNOWLEDGMENTS}

The work described in this publication was supported by the European Community's Sixth Framework Programme through the grant to the budget of the Integrated Project FLOODsite, Contract GOCE-CT-2004-505420.
A wide range of experts have contributed to the research work under Task 4 and these contributions are gratefully acknowledged. This includes contributions from Vojtěch Beneš, Zuzana Boukalová, Mark Dyer, Pieter van Gelder, Randa Hassan, Semeidi Husrin, Hans-Jörg Lambrecht, Grzegorz Stanczak, Jentsje van der Meer, Stefano Utily, Paul Visser and Martin Young.

\section{REFERENCES}

Boukalová, Z. and Beneš, V. (2008). Application of GMS System in the Czech Republic-Practical use of IMPACT, FLOODsite and GEMSTONE project outcomes. FLOODrisk2008 conference, Oxford, UK. 302nd October, 2008.

Buijs, F.A. (2008), Time-dependent reliability analysis of flood defences, $\mathrm{PhD}$ thesis, University of Newcastle-upon-tyne.

CIRIA (1987), Design of reinforced grass waterways, Report 116, CIRIA.

CIRIA, (1996), Beach Management manual, Report 153, CIRIA.

FLOODsite (2007a), Failure mechanisms for flood defence structures, FLOODsite Report T04-06-01, Task 4. www. FLOODsite.net

FLOODsite (2007b), ComCoast WP3: Phase 3: Design, construction and calibration of a wave overtopping simulator. FLOODsite Report T04-07-05, Task 4. www. FLOODsite.net

FLOODsite (2007c). Air trapping phenomenon and cracking-model tests on an embankment. FLOODsite report T04-07-10, Task 4. February 2007. www. FLOODsite.net

FLOODsite (2007d). Failure mechanisms of shingle barrier beaches. FLOODsite report T04-08-02, Task 4. September, 2007. www.FLOODsite.net

FLOODsite (2008), Reliability Analysis of Flood Sea Defence Structures and Systems, edited by: Tudelft, Delft, the Netherlands.

HR Wallingford (2004), Performance and Reliability of Flood and Coastal Defences_-Phase I, A review of Flood and Coastal Defence failures and failure processes, R\&D interim technical report, HR Wallingford.

IMPACT (2005), IMPACT Project WP6: Geophysical investigation techniques. March 2005. www.impact-project.net

Morris, M.W., Kortenhaus, A., Visser, P., Hassan, M.A.A.M Geisenhainer, P. and Zhu, Y (2008). Modelling breach initiation and growth. FLOODrisk2008 conference, Oxford, UK. 30-2ndOctober, 2008.

Powel, K.A., (1990). Predicting short term profile response for shingle beaches, Report SR219, HR Wallingford.

Vellinga, P., (1986). Beach and dune erosion during storm surges. Thesis Delft University of Technology, also: Delft Hydraulics, Communications No.372, The Netherlands.

Young, M.J., (2005). Wave overtopping and grass cover layer failure on the inner slopes of dikes. UNESCO-IHE MSc thesis WSE-CEPD-05.03. June 2005. 


\title{
Fluid thinking...smart solutions
}

HR Wallingford provides world-leading analysis, advice and support in engineering and environmental hydraulics, and in the management of water and the water environment. Created as the Hydraulics Research Station of the UK Government in 1947, the Company became a private entity in 1982, and has since operated as a independent, non profit distributing firm committed to building knowledge and solving problems, expertly and appropriately.

Today, HR Wallingford has a 50 year track record of achievement in applied research and consultancy, and a unique mix of know-how, assets and facilities, including state of the art physical modelling laboratories, a full range of computational modelling tools, and above all, expert staff with world-renowned skills and experience.

The Company has a pedigree of excellence and a tradition of innovation, which it sustains by re-investing profits from operations into programmes of strategic research and development designed to keep it - and its clients and partners - at the leading edge.

Headquartered in the UK, HR Wallingford reaches clients and partners globally through a network of offices, agents and alliances around the world.

\section{HR Wallingford}

Working with water

\author{
HR Wallingford Ltd \\ Howbery Park \\ Wallingford \\ 0xfordshire 0X10 8BA \\ UK
tel $\quad+44(0) 1491835381$
fax +44 (0)1491832233
email info@hrwallingford.co.uk

\section{www.hrwallingford.co.uk}

